\title{
Cross-resistance to five glucocorticoids in childhood acute lymphoblastic and non-lymphoblastic leukemia samples tested by the MTT assay: Preliminary report ${ }^{\star \star}$
}

Jan Styczyński ${ }^{1, 凶}$, Mariusz Wysocki ${ }^{1}$, Robert Dębski ${ }^{1}$, Walentyna Balwierz ${ }^{2}$, Roma Rokicka-Milewska ${ }^{3}$, Michał Matysiak ${ }^{4}$, Anna Balcerska ${ }^{5}$, Jerzy Kowalczyk ${ }^{6}$, Jacek Wachowiak ${ }^{7}$, Danuta Sońta-Jakimczyk ${ }^{8}$ and Alicja Chybicka ${ }^{9}$

${ }^{1}$ Department of Pediatric Hematology and Oncology, Medical University, Bydgoszcz, Poland;

${ }^{2}$ Department of Pediatric Hematology, Collegium Medicum Jagiellonian University, Kraków, Poland; ${ }^{3}$ Department of Pediatric Hematology and Oncology, ${ }^{4}$ Department of Pediatric Pulmonology, Alergology and Hematology, Medical University, Warszawa, Poland; ${ }^{5}$ Department of Pediatric Hematology, Oncology and Endocrinology, Medical University, Gdańsk, Poland; ${ }^{6}$ Department of Pediatric Hematology and Oncology, Medical University, Lublin, Poland; ${ }^{7}$ Department of Pediatric Hematology and Oncology, Medical University, Poznań, Poland; ${ }^{8}$ Department of Pediatric Hematology and Chemotherapy, Silesian Medical University, Zabrze, Poland; ${ }^{9}$ Department of Pediatric Hematology and Oncology, Medical University, Wrocław, Poland

Received: 10 September, 2001; revised: 03 January, 2002; accepted: 21 February, 2002

Key words: glucocorticoid resistance, MTT assay, acute leukemia, ALL, AML, cross-resistance, sensitivity

In vitro antileukemic activity of five glucocorticoids and their cross-resistance pattern in childhood acute lymphoblastic and non-lymphoblastic leukemia were determined by means of the MTT assay in 25 leukemia cell samples of childhood acute leukemias. The equivalent antileukemic concentrations of the drugs tested were: $34 \mu \mathrm{M}$ hydrocortisone (HC), $8 \mu \mathrm{M}$ prednisolone (PRE), $1.5 \mu \mathrm{M}$ methylprednisolone

\footnotetext{
${ }^{\star}$ Presented at the 8th International Symposium on Molecular Aspects of Chemotherapy, September, 2001, Gdańsk, Poland.

The study was supported by the State Committee for Scientific Research (KBN, Poland) grant 6 P05E 08221 and performed in the Laboratory of Clinical and Experimental Oncology, Department of Pediatric Hematology and Oncology, Medical University Bydgoszcz, Poland.

${ }^{凶}$ Address for correspondence: Jan Styczyński, W. Gersona 17-8, 85-305 Bydgoszcz, Poland; fax: (48 52) 585 4867; e-mail: jan styczynski@kki.net.pl

Abbreviations: ALL, acute lymphoblastic leukemia; iALL, initial ALL; rALL, relapsed ALL; AML, acute myeloblastic leukemia; BET, betamethasone; BM, bone marrow; DX, dexamethasone; HC, hydrocortisone; MPR, methylprednisolone; PB, peripheral blood; PRE, prednisolone; RR, relative resistance.
} 
(MPR), $0.44 \mu \mathrm{M}$ dexamethasone (DX) and $0.22 \mu \mathrm{M}$ betamethasone (BET). In comparison with initial ALL cell samples, the relapsed ALL group was more resistant to PRE (38-fold, $p=0.044)$, DX (> 34-fold, p = 0.04), MPR (38-fold), BET (45-fold) and HC (33-fold). The AML cell samples were even more resistant to: $\mathrm{PRE}$ ( $>85$-fold, $\mathrm{p}=0.001$ ), DX ( $>$ 34-fold, $p=0.004)$, MPR ( $>69$-fold, $p=0.036)$, BET $(>69$-fold, $p=0.038)$ and HC (54-fold, $p=0.059$ ) when compared with ALL on initial diagnosis. A significant cross-resistance among all the glucocorticoids used was found. Only in some individual cases the cross-resistance was less pronounced.

Glucocorticoids are important drugs in therapy of acute lymphoblastic leukemia (ALL) but resistance to those agents is a major obstacle in the progress of anti-leukemic therapy. On the other hand, this group of drugs is not used in therapy of acute myeloblastic leukemia (AML) due to clinical resistance of myeloblasts. Resistance in vitro and in vivo to glucocorticoids is nowadays one of the strongest adverse risk factors in the treatment of childhood acute lymphoblastic leukemia [1-2]. Based on the results obtained both with experimental cell lines and patients' leukemic cell samples, the most important resistance mechanisms to glucocorticoids include: abnormalities in number, morphology and function of glucocorticoid receptors [3-4], upregulation of transmembrane P-glycoprotein [5], intracellular level of glutathione and its $S$-transferases [6], changes in DNA repair processes [7], heat shock proteins expression [8], and apoptosis disregulation, especially in the mitochondrial pathway [3]. Future clinical possibilities to overcome the resistance to glucocorticoids include the use either of resistance modifiers or a drug with the highest anti-leukemic activity for individual patient. Possible modulation of resistance, including administration of a modifier together with the glucocorticoid, is still far from clinical practice. On the other hand, the role and the use of prednisolone and dexamethasone in different therapeutic protocols for childhood ALL is not yet strictly established. Differential cytotoxicity of those drugs against human lymphoblasts has been reported in several studies [9-11].
The objective of the study was the determination of antileukemic activity and cross-resistance pattern among five various glucocorticoids in samples of childhood acute leukemia. In addition to prednisolone and dexamethasone, the basic drugs in the therapy of ALL, we tested three glucocorticoids which are in common use in treatment of numerous non-proliferative diseases, due to their anti-inflammatory properties: hydrocortisone, methylprednisolone and betamethasone.

\section{MATERIAL AND METHODS}

Leukemic cells were from children with acute lymphoblastic leukemia on diagnosis (iALL, $\mathrm{n}=13)$, rALL on relapse $(\mathrm{n}=6)$ and with acute non-lymphoblastic leukemia on diagnosis (iAML, $n=6$ ). The analyzed group of patients consisted of 17 boys and 8 girls, aged 0.6-18 yrs (median 9 yrs). Each patient was included only once in the study.

In vitro drug resistance was established by means of the MTT assay [12]. The following glucocorticoids were tested: prednisolone (PRE), dexamethasone (DX), betamethasone (BET), methylprednisolone (MPR) and hydrocortisone (HC) (Table 1, Scheme 1). Drug concentration lethal to $50 \%$ of tested cells $\left(\mathrm{LC}_{50}\right)$ was used as a measure of cytotoxicity. Differences between groups were compared with Mann-Whitney U test. Cross-resistance between the cytotoxicity of each pair of drugs was determined by Spearman's rho coefficient of correlation. The study was approved by the Local Ethics Committee, Medical University, Bydgoszcz. 
Table 1. Drugs and concentrations tested

\begin{tabular}{llll}
\hline & \multicolumn{2}{l}{ Molecular mass } & \multicolumn{2}{l}{ Concentration range } \\
\cline { 2 - 4 } & {$[\mathrm{g} / \mathrm{mol}]$} & {$[\mu \mathrm{g} / \mathrm{ml}]$} & {$[\mu \mathrm{M}]$} \\
\hline Betamethasone & 392.0 & $0.000183-6$ & $0.5 \mathrm{nM}-15.3$ \\
Dexamethasone & 392.0 & $0.000183-6$ & $0.5 \mathrm{nM}-15.3$ \\
Methylprednisolone & 374.4 & $0.0012207-40$ & $3.2 \mathrm{nM}-106.8$ \\
Prednisolone & 360.0 & $0.007629-250$ & $0.0212-694$ \\
Hydrocortisone & 362.5 & $0.0244141-800$ & $0.0673-2.2 \mathrm{mM}$ \\
\hline
\end{tabular}<smiles>CC12CCC(=O)C=C1CC[C@H]1C3CC[C@@](C)(C(=O)CO)[C@@]3(O)CC[C@@H]12</smiles>

CORTISOL (HYDROCORTISONE)<smiles>C[C@]1(C(=O)CO)CC[C@@H](O)[C@H]2[C@H]1CCC1=CC(=O)C=C[C@@]12C</smiles>

PREDNISOLONE

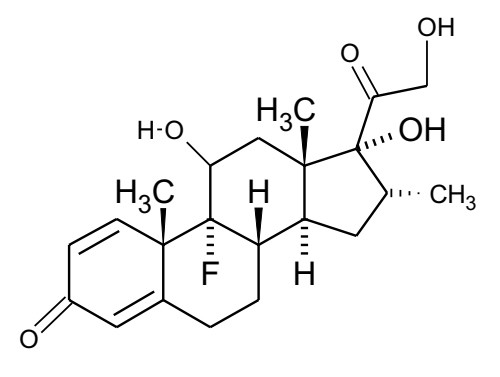

DEXAMETHASONE<smiles>C[C@]12C=CC(=O)C=C1CC[C@@H]1[C@@H]2C(=O)C[C@]2(C)[C@@H]1CC[C@]2(O)C(=O)CO</smiles>

PREDNISONE<smiles>CC1C[C@H]2C[C@H]3C(O)CC4(C)[C@@H](CC[C@]4(O)C(=O)CO)[C@H]3C2(C)C=CC1=O</smiles>

METHYLPREDNISOLONE

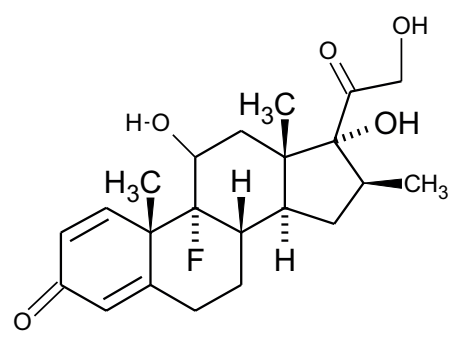

BETAMETHASONE

Scheme 1. Chemical structure of glucocorticoids

\section{RESULTS}

The equivalent antileukemic concentrations of the drugs tested were: $34 \mu \mathrm{M} \mathrm{HC}, 8 \mu \mathrm{M}$ PRE, $1.5 \mu \mathrm{M}$ MPR, $0.44 \mu \mathrm{M}$ DX and $0.22 \mu \mathrm{M}$
BET. In comparison with initial ALL samples, the relapsed group of ALL was more resistant to PRE (38-fold, $\mathrm{p}=0.044), \mathrm{DX}$ ( $>$ 34-fold, $\mathrm{p}$ = 0.04), MPR (38-fold), BET (45-fold) and HC (33-fold). The AML group of patients was even 
more resistant to PRE (> 85-fold, $\mathrm{p}=0.001)$, DX ( $>$ 34-fold, p = 0.004), MPR ( $>$ 69-fold, $\mathrm{p}=0.036)$, BET $(>69$-fold, $\mathrm{p}=0.038)$ and $\mathrm{HC}$ (54-fold, $\mathrm{p}=0.059$ ) compared with the ALL on initial diagnosis group (Table 2). A significant lower than $1 / 2$ of the highest concentration tested. In 5/6 AML cases maximum resistance to PRE and DX was seen. In four cases, even a stimulation by at least one glucocorticoid of myeloblast growth was observed.

Table 2. Median cytotoxicity $\left(\mathrm{LC}_{50}\right)$ and relative resistance to glucocorticoids

\begin{tabular}{llllll}
\hline & \multicolumn{3}{l}{$\mathrm{LC}_{50}[\mu \mathrm{M}]$} & \multicolumn{3}{l}{ Relative resistance (RR) } \\
\hline & $\mathrm{iALL}$ & rALL & iAML & RR(rALL $v$ s iALL) & RR (iAML $v$ s iALL) \\
\cline { 2 - 6 } Betamethasone & 0.22 & 9.8 & $>15.3$ & $44.8 ; \mathrm{p}=0.072$ & $>69 ; \mathrm{p}=0.038$ \\
Dexamethasone & 0.44 & $>15.3$ & $>15.3$ & $>34.2 ; \mathrm{p}=0.040$ & $>34.2 ; \mathrm{p}=0.004$ \\
Methylprednisolone & 1.55 & 59.5 & $>106.8$ & $38.4 ; \mathrm{p}=0.15$ & $>69 ; \mathrm{p}=0.036$ \\
Prednisolone & 8.1 & 308.3 & $>694$ & $38.0 ; \mathrm{p}=0.044$ & $>85 ; \mathrm{p}=0.001$ \\
Hydrocortisone & 34.7 & 1155 & 1894 & $33.0 ; \mathrm{p}=0.13$ & $54 ; \mathrm{p}=0.059$ \\
\hline
\end{tabular}

$\mathrm{RR}$, relative resistance in comparison with iALL; $\left({ }^{*}\right) \mathrm{RR}$ is the median $\mathrm{LC}_{50}$ for $\mathrm{rALL}$ divided by the median $\mathrm{LC}$ 50 for iALL; (**) $\mathrm{RR}$ is the median $\mathrm{LC}_{50}$ for iAML divided by the median $\mathrm{LC}_{50}$ for iALL; RR >1 indicates that for the given drug, rALL (iAML) is more resistant than iALL; $p$, Mann-Whitney U test.

cross-resistance between all glucocorticoids used was observed (Table 3). In some individual cases the cross-resistance was less pronounced.

A significant correlation was observed between the cytotoxicities of structurally similar drugs, such as DX and BET (Table 3). In 3/6 AML cases maximum resistance to all five glucocorticoids was observed; in all other cases, except one, the $\mathrm{LC}_{50}$ values were not
In one case, however, good sensitivity to BET was observed.

\section{DISCUSSION}

Resistance to glucocorticoids can play a role in pathogenesis of various diseases, such as autoimmunologic disorders, AIDS, Nelson syndrome, sclerosis multiplex and leukemias

Table 3. Correlation matrix of glucocorticoids cross-resistance

\begin{tabular}{llllll}
\hline & PRE & DX & BET & MPR & HC \\
\hline PRE & & 0.625 & 0.550 & 0.407 & 0.525 \\
& & 0.001 & 0.008 & 0.043 & 0.007 \\
DX & 0.625 & & 0.681 & 0.352 & 0.639 \\
& 0.001 & & $<0.001$ & 0.084 & 0.001 \\
BET & 0.550 & 0.681 & & 0.461 & 0.690 \\
& 0.008 & $<0.001$ & & 0.031 & $<0.001$ \\
MPR & 0.407 & 0.352 & 0.461 & & 0.693 \\
& 0.043 & 0.084 & 0.031 & & $<0.001$ \\
HC & 0.525 & 0.639 & 0.690 & 0.693 & \\
& 0.007 & 0.001 & $<0.001$ & $<0.001$ & \\
\hline
\end{tabular}

Upper value in each area is the value of Spearman's rho coefficient of correlation of $\mathrm{LC}_{50}$ values for a pair of drugs, lower value - $p$, value of this coefficient. PRE, prednisolone; DX, dexamethasone; BET, betamethasone; MPR, methylprednisolone; $\mathrm{HC}$, hydrocortisone. 
[13]. Recent studies demonstrate that primary (hereditary) abnormalities in the glucocorticoid receptor gene make $6.6 \%$ of the normal population relatively 'hypersensitive' to glucocorticoids, while $2.3 \%$ are relatively "resistant". These abnormalities might explain the well-known phenomenon that some individuals develop severe adverse effects during therapy with a low dose of glucocorticosteroids, while others do not develop side effects even during long-term therapy with a much higher dose [14]. In childhood ALL in vitro glucocorticoid resistance is observed in $41-48 \%$ patients on diagnosis. After repeated cycles of chemotherapy including glucocorticoids, the rate of glucocorticoid resistance reaches $60-90 \%$ patients at relapse $[1,15]$. The sensitivity to glucocorticoids is thought to be one of the most important prognostic factors in various therapeutic protocols for children with ALL. Prednisolone resistance is thought to be the strongest single adverse prognostic factor [1-2, 9-11, 15]. Glucocorticoids are the most important cytotoxic drugs in the therapy of ALL. Recent studies have shown that the response of ALL to glucocorticoid therapy increases with drug dose. High-dose corticosteroid treatment abrogates the effect of relative drug insensitivity and of low glucocorticoid receptor number on peripheral blasts [16].

In our study, based solely on clinical material, we determined in vitro cross-resistance pattern between prednisolone, dexamethasone, betamethasone, methylprednisolone and hydrocortisone in samples from childhood acute leukemia. We showed that betamethasone, methylprednisolone and hydrocortisone cannot circumvent resistance to prednisolone and dexamethasone in childhood ALL and even showed worse activity against AML, with a possible exception of betamethasone. We observed that each of the glucocorticoids tested could stimulate in vitro proliferation of myeloblasts in 4-day culture, similar to the results of another study [17]. We noticed, however, that in individual pa- tients cells could be identified as sensitive to betamethasone but resistant to prednisolone or dexamethasone. An additional observation of the present study is that DX has a 17 -fold higher antileukemic potency than PRE, which was suggested earlier [10]. The activity of BET against leukemic cells was found to be 2-fold higher than that of DX. These results suggest that antileukemic properties of the glucocorticoids tested may differ from their anti-inflammatory activity, as DX is usually thought to be 7-fold more active than PRE, and BET about 1.5-fold more active than DX. In conclusion, the results of the study suggest that a subgroup of patients with leukemia can be recognized, for whom the individual profile of cytotoxicity to glucocorticoids can help to choose the drug with the highest antileukemic potency and possibly more favourable pharmacokinetics.

Authors thank Beata Kołodziej for technical assistance.

\section{R E F E R E N C E S}

1. Kaspers, G.J., Pieters, R., Klumper, E., De Waal, F.C. \& Veerman, A.J. (1994) Glucocorticoid resistance in childhood leukemia. Leuk. Lymphoma 13, 187-201.

2. Schrappe, M., Reiter, A., Ludwig, W.D., Harbott, J., Zimmermann, M., Hiddemann, W., Niemeyer, C., Henze, G., Feldges, A., Zintl, F., Kornhuber, B., Ritter, J., Welte, K., Gadner, H. \& Riehm, H. (2000) Improved outcome in childhood acute lymphoblastic leukemia despite reduced use of anthracyclines and cranial radiotherapy: Results of trial ALLBFM 90. German-Austrian-Swiss ALL-BFM Study Group. Blood 95, 3310-3322.

3. Kofler, R. (2000) The molecular basis of glucocorticoid-induced apoptosis of lymphoblastic leukemia cells. Histochem. Cell Biol. 114, 1-7.

4. Longui, C.A., Vottero, A., Adamson, P.C., Cole, D.E., Kino, T., Monte, O. \& Chrousos, 
G.P. (2000) Low glucocorticoid receptor alpha/beta ratio in T-cell lymphoblastic leukemia. Hormone Metab. Res. 32, 401-406.

5. Gruol, D.J., Vo, Q.D. \& Zee, M.C. (1999) Profound differences in the transport of steroids by two mouse P-glycoproteins. Biochem. Pharmacol. 58, 1191-1199.

6. Hala, M., Hartmann, B.L., Bock, G., Geley, S. \& Kofler, R. (1999) Glucocorticoid-receptorgene defects and resistance to glucocorticoid-induced apoptosis in human leukemic cell lines. Int. J. Cancer 68, 663-668.

7. Biswas, T., Ramana, C.V., Srinivasan, G., Boldogh, I., Hazra, T.K., Chen, Z., Tano, K., Thompson, E.B. \& Mitra, S. (1999) Activation of human $O^{6}$-methylguanine-DNA methyltransferase gene by glucocorticoid hormone. Oncogene 18, 525-532.

8. Creagh, E.M., Sheehan, D. \& Cotter, T.G. (2000) Heat shock proteins - modulators of apoptosis in tumour cells. Leukemia 14, 1161-1173.

9. Ito, C., Evans, W.E., McNinch, L., CoustanSmith, E., Mahmoud, H., Pui, C.H. \& Campana, D. (1996) Comparative cytotoxicity of dexamethasone and prednisolone in childhood acute lymphoblastic leukemia. J. Clin. Oncol. 14, 2370-2376.

10. Kaspers, G.J., Veerman, A.J., Popp-Snijders, C., Lomecky, M., Van Zantwijk, C.H., Swinkels, L.M., Van Wering, E.R. \& Pieters, R. (1996) Comparison of the antileukemic activity in vitro of dexamethasone and prednisolone in childhood acute lymphoblastic leukemia. Med. Pediatr. Oncol. 27, 114-121.

11. Mihal, V., Hajduch, M., Noskova, V., Feketova, G., Jess, K., Gojova, L., Kasparek, I., Stary, J., Blazek, B., Pospisilova, D. \& Novak, Z. (1999) Differential antileukemic activity of predniso- lone and dexamethasone in freshly isolated leukemic cells. Adv. Exp. Med. Biol. 457, 461-471.

12. Styczyński, J., Pieters, R., Huismans, D.R., Schuurhuis, G.J., Wysocki, M. \& Veerman, A.J.P. (2000) In vitro drug resistance profiles in adult versus childhood acute lymphoblastic leukaemia. Br. J. Haematol. 110, 813-818.

13. DeRijk, R. \& Sternberg, E.M. (1997) Corticosteroid resistance and disease. Ann. Med. 29, 79-82.

14. Lamberts, S.W.J., Huizinga, A.T.M., De Lange, P., De Jong, F.H. \& Koper, J.W. (1996) Clinical aspects of glucocorticoid resistance. Steroids 61, 157-160.

15. Hongo, T., Yamada, S., Yajima, S., Watanabe, C., Fuji, Y., Kawasaki, H., Yazaki, M., Hanada, R. \& Horikoshi, Y. (1999) Biological characteristics and prognostic value of in vitro three-drug resistance to prednisolone, L-asparaginase, and vincristine in childhood acute lymphoblastic leukemia. Int. J. Hematol. 70, 268-277.

16. Schwartz, C.L., Thompson, E.B., Gelber, R.D., Young, M.L., Chilton, D., Cohen, H.J. \& Sallan, S.E. (2001) Improved response with higher corticosteroid dose in children with acute lymphoblastic leukemia. J. Clin. Oncol. 19, 1040-1046.

17. Zwaan, C.M., Kaspers, G.J.L., Pieters, R., Ramakers-Van Woerden, N.L., Den Boer, M.L., Wunsche, R., Rottier, M.M.A., Hahlen, K., Van Wering, E., Janka-Schaub, G.E., Creutzig, U. \& Veerman, A.J.P. (2000) Cellular drug resistance profiles in childhood acute myeloid leukemia: Differences between FAB types and comparison with acute lymphoblastic leukemia. Blood 96, 2879-2886. 